\title{
Chapter 13 \\ Looking at the Present Through the Future: Science-Fiction Urbanism and Contingent and Relational Creativity ${ }^{1}$
}

\author{
Rob Kitchin
}

Writing fiction is a creative act. It involves the production of a narrative that tells a fictional story. Although much fiction is derivative of stories that have preceded it, and although much of it is clichéd, shallow, and uninspired, there is a steady stream of new works that continue to push boundaries with respect to style, substance, and foci. They are stories that are creative in ways that extend beyond the act of simply making something. Rather than being citational, imitative, and stereotypical (where the plot lines and characters are similar to much of the fiction that had preceded), they are genuine attempts to challenge conventional tropes and styles and to say something meaningful about the world (rather than simply entertain). They are works that are insightful, surprising, educational, interesting, exciting, and enlightening; they interpolate (fill in holes) and extrapolate (make fragments into a whole); and they might be intertextual, but in knowing, clever, witty, and meaningful ways. They make their readers look at the world afresh with new perspectives.

Such creative acts, I argue, do not arise out of nowhere, from some innate product of a novelist's biological make-up (and thus are not measureable in some reductionist way through psychological testing). Instead, their creativity is a product of the writer's skills and talents coupled with their embeddedness in networks of people, things, and places. These networks profoundly shape the fiction of creative acts. Writers learn the various facets of how to write-literacy, grammar, punctuation, composition, observation, translation (the process of taking knowledge of the world and converting it into a narrative), imagination, and speculation-of how to engage critically with philosophy, ideology, aspects of the human condition, and so on. Whereas some individuals might possess great talent and skill, these supposed "gifts" are nurtured, shaped, and encouraged by diverse factors such as schooling, tutoring in literary theory and praxis, exposure to other writers' work, and encouragement and critical feedback from peers. And although some writers might claim

R. Kitchin $(\bowtie)$

National Institute for Regional and Spatial Analysis, Hume Building, NUL, Maynooth,

Co. Kildare, Ireland

e-mail: Rob.Kitchin@nuim.ie

${ }^{1}$ Parts of this chapter are based on previously published work (see Dodge \& Kitchin, 2000; Kitchin \& Kneale, 2001; Kneale \& Kitchin, 2002). 
to have had no formal training in creative writing, their abilities to craft a story has nonetheless been nurtured in informal ways. Nobody sits down to write as a fully formed writer. And a story derives its inspiration, focus, and politics from its writer's life experiences and engagements with people and places.

Take the novel Frankenstein, written by Mary Shelley and published 1818. It is a profoundly creative and imaginative work that provided the genesis for the genre of science fiction (Malmgren, 1991). The story and Shelley's ability to write it did not come from nowhere; they were not the product of an innately talented mind. Rather, the book was a product of Shelley's schooling, her engagements with other fiction, and her relations and discussions with the set of literary figures who constituted her circle of friends (Lord Byron, Dr. John Polidori, and Percy Shelley). It sprang from her travels around Europe and her reading of the cultural landscape. (Frankenstein was written in Geneva, with the Alps and locales such as Chillon Castle providing inspiration.) It issued from her knowledge and understanding of the radical changes occurring around her: the age of Enlightenment, the incipient industrial revolution, the development of rational scientific practice, and a growing sense of how science could advance society and how the future could be extrapolated from the present. Indeed, Shelley herself acknowledges in the introduction to the 1831 edition that the idea for the novel stemmed from a challenge to write a ghost story after she and her friends had read Fantasmagoriana, ou Recueil d'histoires d'apparitions de spectres, revenants, fantômes, etc. (Eyries, 1812), a French translation of a German book of ghost stories. A subsequent set of conversations about the scientific work of Erasmus Darwin and Luigi Galvani contributed the scientific underpinnings for the story. At later stages various drafts would have been read by friends, editors, and others, with edits then being applied to the text. Frankenstein was therefore the product of a complex engagement between Shelley and the world at a particular time and place.

Just as other actors and actants (objects and items that have agency, such as various technologies and tools) shape writers, fiction itself does work in the world. Not only does it entertain, it affords a discursive medium of ideas that act as sources of insight and inspiration. This discursive work is sometimes acknowledged explicitly by others, perhaps through statements or interviews ("I have been profoundly influenced by the writings of ...," as in Mary Shelley's case). In other instances it is implicitly acknowledged through intertextuality or imitation. Fiction is therefore an actant in the creative processes of other actors (e.g., teachers, journalists, engineers, urban planners, artists, and other novelists), often in ways that were never intended by the novelist. Nearly 200 years after the publication of Frankenstein, the novel and its ideas are still actively at work in the world. The ideas within the story serve as sources of film adaptations, derivative stories (e.g., The Bride of Frankenstein), and inspiration for a slew of other horror stories and films, not to mention the biotechnology sector-including the opponents of gene modification (GM) and animal testing. It is no coincidence that this protest movement has labeled genetically modified crops "Frankenstein crops" to highlight their "unnatural" and "monstrous" qualities (see Bingham, 2002). This kind of science and the protests it incites are fresh stimuli and substantive issues for fiction writers. In other words, a recursive relationship can develop between fiction and fact. 
This chapter is an exploration of the creative writing by several science-fiction writers. I illustrate ways in which their writing emerges from diverse engagements with the world, how their fiction does work in the world, and how a recursive relationship has in some cases developed between novelists and people who read and act upon their stories. The empirical material for my argument comes from a project that involved analysis of 34 novels and four collections of short stories with plots focusing on the development and use of cyberspatial, virtual reality, other information and communication technologies (ICTs), and issues such as telemediation, computer intelligence, surveillance and governance, person-machine relations (cyborgs), and the changing nature of work and urbanism (see Dodge \& Kitchin, 2000; Kitchin \& Kneale, 2001). All but two of the novels were by North American writers, all but two were by men, all were published between 1982 and 1998, and many belonged to the genre known as "cyberpunk." Of particular interest in this project were the manners in which the novelists dealt with notions of space and time, given the supposed ways in which ICTs "destroy distance." It also described the new geographies of the near future. In this chapter I confine my focus to asking how the authors of these stories imagine urban environments and life and the nature of future cities. I argue that these novelists' visions of the near future serve as a powerful cognitive lens on urbanism in the present, extrapolating from spatial processes that are already at work. This lens is no coincidence; fiction is a product of its place and time, and in some cases ideas are drawn from contemporary urban theory. As I show, this urban theory has, in turn, drawn inspiration from these novels, creating a recursive relationship between novelists and urban theorists.

\section{Introducing Science Fiction and Cyberpunk}

Since the time that science fiction emerged as a specific literary genre with the publication of Frankenstein (Malmgren, 1991), it has grown to become a very large and popular genre with many subgenres focused on particular realms or technologies. Focusing on the near or far future, but rarely set in the present day, science-fiction writers create imaginative worlds in which to explore new sciences and the meaning and nature of life. Suvin (1979) argues that they create a totalizing novum (novelty, innovation)—entire new worlds, either fully imagined ones or this one in the future-by employing extrapolation and speculation. Suvin argues that these tactics create a sense of estrangement for readers by making the familiar strange. Science fiction's appeal is that it opens readers to new ways of thinking and knowing, but in ways that are tempered by scientific rationale and explanation and by social and spatial metaphors that domesticate the implausibility of the narrative. These realms are not purely fantastical worlds, separated from what people understand as reality and what might seem rationally possible (such as with fantasy writing). Instead, they are worlds that seem plausible given where science seems to be heading. "S[cience] F[iction] rigorously and systematically 'naturalizes' or 'domesticates' its displacements and discontinuities" (Malmgren, 1991, p. 6). 
By grounding its science and society in the realities of peoples' experiences, however tenuously, science fiction thus has something about the present and the human condition. It creates a cognitive space, an estrangement between real and fictional worlds, which the reader must negotiate to link this world with that of the author's (Malmgren, 1991). Science fiction thereby creates sites of contemplation and accommodation from which to examine the world and what it might become, a discursive field through which to critically think through the present and the possibilities of the future. This point is acknowledged by science-fiction writers themselves. As stated by Gibson (1989, p. 32), a writer referred to several times in this chapter: "What's most important to me is that it's about the present. It's not really about an imagined future. It's a way of trying to come to terms with the awe and terror inspired in me by the world in which we live". He has also declared that his original ideas for the San Francisco of Virtual Light was "some permutation of the city as it exists today, that might be remotely possible" (Gibson, 1993, p. 32).

In writing such salutary stories, as with Shelley's Frankenstein, science-fiction writers draw on their engagements with the world - their knowledge; experiences; and networks of people, things, and places. It can be no other way. To create feelings of estrangement and defamiliarization, the science and societies they generate have to be grounded in what is presently known and what scientists think is technically possible in the future. Science-fiction writers are therefore often acutely aware of scientific and technological developments. They read scientific journals or follow stories written by science journalists and ask themselves what this technology could mean. What might it make possible? For example, Gibson has noted that his initial inspiration for Neuromancer in the early 1980s came as he watched children play computer-arcade games and subsequently imagined these machines as being connected across distributed networks that could be consciously entered. At the time, such distributed technologies had started to be built beyond the purview of the military forming the nascent Internet, and there was much talk of artificial intelligence and telemediation. Gibson thereupon looked around at the changing nature of cities and processes of globalization and projected the whole lot 30 years into the future. Coupled with a writing style that seemed in tune with the processes and technologies being described, the result was a story that seemed strange and yet familiar, fantastical, but plausible. It opened up new ways to think about the emerging information society.

Gibson's novels were both popular and influential and formed part of a subgenre that developed throughout the 1980s, cyberpunk. Cyberpunk focused almost exclusively on the exploration of the effects that ICTs might have on social, economic, political, and spatial relations. But unlike other types of science fiction that explored similar themes, it was decidedly postmodern in its focus and style. Indeed, literary analysts have argued that cyberpunk was "postmodernist SF" (McCaffery, 1991, p. 1) for three reasons. First, cyberpunk was one of the first forms of literary genre to recognize, reflect, and explore the postmodern condition (e.g., the transformation into a postindustrial society, the creation of hyperreal places and simulacra, the merging of technology and nature). Second, cyberpunk was a decidedly posthumanist orientation exploring the interconnectedness and contingencies in the relationship 
between people and technology (rather than treating them as separate ontological domains). Third, the narrative style was itself decidedly postmodern in character. For example, it often broke with traditional conventions, being discontinual and stitching together different styles and motifs. Cyberpunk was thus seen to destabilize the basic modernist assumptions lying at the core of nineteenth- and twentieth-century science fiction: the dichotomy between self-other; self-society; nature-technology; nature-civilization; rational-irrational; order-chaos; life-death, real-imaginary, and the privileged central position occupied by humans (Hollinger, 1991).

Just as cyberpunk was a product of the world, it did work in the world. In addition to entertaining its readers, cyberpunk challenged them to examine the development of ICTs and the ways in which they had an impact on social and economic relations on a variety of scales. Indeed, the often dystopian stories of the genre prompted readers to think politically and ethically about the new worlds coming about through new technologies that had potentially far-reaching consequences for social formation and modes of governance. As a result, cultural critics such as Jameson (1991) argued that cyberpunk offered privileged insights into contemporary culture, furnishing cognitive maps of the postmodern condition. Many of these readers, in their own working lives, further drew on the ideas and ideologies contained within the novels. In cyberpunk's case this interaction included engineers, politicians, and academics. Cyberpunk was seen as delivering not only powerful social commentary on the present (by extrapolating into the future) but also blueprints for future technologies. This dual outcome was particularly strong in the case of work by Gibson. Some scholars even claim that recent developments in both computing and society can be regarded as an attempt to put his fictional visions into practice. For example, Tomas (1991) and Stone (1991) suggest that Gibson has significantly shaped the information society. As Stone (1991) has stated, Neuromancer "provided ... the imaginal public sphere and reconfigured discursive community that established the grounding for the possibility of a new kind of [person-computer] interaction" (p. 95).

For example, Gibson's trilogy (Neuromancer [1984], Count Zero [1986], and Mona Lisa Overdrive [1988]) inspired John Walker to launch the Autodesk (leading virtual reality developers) "Cyberpunk Initiative" in 1988 (Chesher, 1994). In a white paper entitled "Through the Looking Glass: Beyond User Interfaces," he invoked Gibson to propose a project to produce a visual 3D cyberspace within 16 months. Similarly, Al Gore and other politicians have, somewhat ironically, drawn on Gibson to formulate their own visions and policies of the future and to justify investment in ICT. Gibson himself has noted how his often dystopian fiction is often misread by others who use it to justify other ends:

I was delighted when scientists and corporate technicians started to read me, but I soon realized that all the critical pessimistic left-wing stuff just goes over their heads. The social and political naiveté of modern corporate boffins is frightening, they read me and just take bits, all the cute technology, and miss about fifteen levels of irony. (Gibson, 1989, as cited in Hayward, 1993)

Urban planners have similarly (and rather worryingly) drawn inspiration from cyberpunk's posturban landscapes, which, in turn, partially mirror those created by Dick (Do Androids Dream of Sheep? (1968/1996), which was made into a film 
entitled Bladerunner): "In February, 1990, at a public lecture series on art in Los Angeles, three out of five leading urban planners agreed that they hoped someday Los Angeles would look like the film Blade Runner" (Klein, 1991, p. 147). Here, I want to examine in more detail. But rather than examine the relationship between cyberpunk writers and urban planners, I want to focus on their understanding of cities and their engagement with urban theorists.

\section{Writing Urban Futures}

The themes and processes which a symptomatic reading of cyberpunk reveal are a good deal more insightful than those offered by what now passes for the theoretical and empirical mainstream.... I think that one gets a clearer analytical understanding of contemporary urban processes from a reading of Gibson or Stephenson than one does from a reading of Sassen or Castells. (Burrows, 1997, p. 38, 45)

Cyberpunk authors were almost exclusively American, and by and large they were writing about American and Asian cities. They were doing so in the 1980s and early 1990s, a time of massive deindustrialization, growth in the service economy and ICT-based industries, and rapid globalization. The period was marked by the increasing importance of supranational structures (e.g., the United Nations and the European Union) and specific global cities tied together by distributed, transnational information and by financial, business, and entertainment networks (e.g., New York, Los Angeles, London, Paris, Toyko, Singapore, and Hong Kong). It was also a time of growth in surveillance technologies, new forms of governance, erosion of public space and ideals, and a redrawing of the political map (e.g., the collapse of the Soviet Union and the divisions of Yugoslavia). The fiction of cyberpunk writers reflected these trends to create a near future in which the world has been reconfigured by libertarian capitalism, globalization, and social Darwinism. Their writing captured a milieu in which the economy is dominated by a few large multinationals and a panoply of informal businesses, where countries have divided into weak nation-states and where fractured and fragmented cities are tied into a new global order. It was a place where the middle-class has been eliminated and the population neatly divided into haves and have-nots, with the wealthy living in private and defensible spaces, public space no longer existing, and the poor subsisting in ungoverned, anarchic, lawless spaces.

For example, in the fiction of Neal Stephenson and William Gibson, processes of decentralisation, fueled by a collapse of place-based politics and the destruction of the middle class, ${ }^{2}$ produce sprawling, centerless, heterogeneous urban landscapes composed of small enclaves where "old cities were doomed, except possibly as theme parks" (Stephenson, 1995, p. 71). Urban space becomes a large, decentralized sprawl with pockets of highly centralized and dense city spaces: "Home was

\footnotetext{
2 "There's only two kinds of people. People can afford hotels like that, they're one kind. We're the
} other. Used to be, like, a middle class, people in between. But not anymore" (Gibson, 1992, p. 123). 
BAMA, the Sprawl, the Boston-Atlanta Metropolitan Axis" (Gibson, 1984, p. 57). In such environments, places away from the center have become financially unviable and form twenty-first-century ghost towns, "fallen-in edge-cities, the kind of place that went down when the Euro-money imploded" (Gibson, 1992, p. 245), and decaying rust-belt areas. For the poor, locked out of the gleaming, ordered, private, and regulated spaces of defense, spaces become "jury-rigged and jerry-built from scraps" (Gibson, 1988, p. 31), jumbled, heterogeneous spaces growing in upon themselves. In Neuromancer, Case resides in Chiba City, a seedy, low-rent, criminalized Toyko edge-city; in Count Zero, Bobby lives in The Projects, which are run-down, forgotten, and disenfranchised large-scale public housing, home to the underclass and gang culture. In Virtual Light the (Golden Gate) Bridge can no longer carry vehicles because it has been damaged by an earthquake. It is left to decay until the city's homeless take it over and begin to squat there:

The integrity of the span was rigorous as the modern program itself, yet around this had grown another reality, intent upon its own agenda. This had occurred piecemeal, to no set plan, employing every imaginable technique and material. The result was something amorphous, startlingly organic. At night, illuminated by recycled neon, by torchlight, it possessed a queer medieval energy. By day, seen from a distance, it reminded him of the ruin of England's Brighton Pier, as though viewed through some cracked kaleidoscope of vernacular style.

Its steel bones, its stranded tendons, were lost within an accretion of dreams: tattoo parlours, gaming arcades, dimly lit stalls stacked with decaying magazines, sellers of fireworks, of cut bait, betting shops, sushi bars, unlicensed pawnbrokers, herbalists, barbers, bars. Dreams of commerce, their locations generally corresponding with the decks that had once carried vehicular traffic; while above them, rising to the very peaks of the stable towers, lifted the intricately suspended barrio, with its unnumbered population and its zones of more private fantasy. (Gibson, 1992, pp. 58-59)

In the case of the bridge, Gibson's visions were drawn from Kowloon Walled City (or Hak Nam), an anarchic space within pre-handover Hong Kong where up to 33,000 people were packed into little more than 6.5 acres, the shantytowns of developing countries, and the projects of developed countries. Such visions reappear in Williams (1996). He also envisaged Western cities fragmenting into spaces of the haves and have nots, depicted spaces where capital and state invested and regulated or where free-market survival exists, and imagined what would happen if slum areas were left to their own devices and if homelessness continued to grow unchecked:

Orlando scrunched down in his seat so he could see the hammock city. He had long been fascinated by the multi-level shantytowns, sometimes called 'honeycombs' by their residents - or 'rats' nests' by the kind of people who lived in Crown Heights.... Long ago, he had discovered, during the first great housing crisis at the beginning of the century, squatters had begun to build shantytowns beneath the elevated freeways, freeform agglomerations of cardboard crates, aluminum siding, and plastic sheets. As the ground beneath the concrete chutes filled up with an ever-thickening tide of the dispossessed, later arrivals began to move upward into the vaulting itself, bolting cargo nets, canvas tarpaulins, and military surplus parachutes onto the pillars and undersides of the freeway. Rope walkways soon linked the makeshift dwellings, and ladders linked the shantytown below with the one growing above. (p. 510) 
In contrast to the sprawling suburbs of the urban centers, the value of space forces development both upwards and underground, producing a vertical spectrum of stylized, mirrored, postmodern architecture - a riot of glass and steel. Besher (1994) thus describes Toyko:

Sure enough, immense mounds dotted the landscape as far as the eye could see. Gobi guessed these were underground cities. The freeway suddenly dipped. To Gobi's surprise, they were now traveling through the guts of one of these mound cities. The elevated maglev freeway had suddenly become a transparent artery. They flew through a tube at a height about 30 stories above base level. All along both sides of the tube were rows of internal high rises. These high rises were spread-eagled over a series of parks and urban work-play centers.... He caught his breath. They had finally arrived in downtown Neo-Toyko, the circuit-board heart of the rim. Gobi saw wave after wave of towers. Some of them were 500 stories tall, soaring to a point almost above the earth's atmosphere. He saw the famous Aeropolis skyrise, much larger than life but no different than the postcard image that was famous all over the world. Like a skeletal Mt. Fuji constructed of living tubes, it was a man-made volcano that pulsed and breathed in an awesome symmetry of life and death. Half-a-million people lived on its top floors and commuted from one vector to another. (p. 211, 213)

Portraying a futuristic Singapore, Sterling (1988) writes:

It was like downtown Houston. But more like Houston than even Houston had ever had the nerve to become. It was an anthill, a brutal assault against any sane sense of scale. Nightmarishly vast spires whose bulging foundations covered whole city blocks. Their upper reaches were pocked like waffle irons with triangular bracing. Buttresses, glass-covered superhighways, soared half a mile above sea level. ... Story after story rose silent and dreamlike, buildings so unspeakably huge that they lost all sense of weight; they hung above the earth like Euclidean thunderheads, their summits lost in sheets of steel-gray rain. (p. 215)

These buildings are more than mere glass and steel, however. They are virtualized through the incorporation of computer networks that render them "smart." They are "buildings with advanced infrastructure, buildings with the late twenty-first century embedded in their diamond bones and fiber-optic ligaments" (Sterling, 1996, p. 139).

These images are visions of the future that strongly resonate in academic observations of the time. Academics were writing about the new international division of labor; the globalization of trade and labor; deregulation, strategic takeovers and buyouts, backofficing, and teleworking; the growth in neoliberalization and the privatization of state functions; the development of entrepreneurial cities and new, postmodern cityscapes; the new global ordering and connectivity between cities; the fragmentation of cities along wealth lines; the growth in the new poor; the erosion of public space; deterritorialization; the rescaling of politics; and contested spaces from the local level to the global.

This resonance should come as no surprise. Science-fiction writers and academics were observing and writing about the same things. They were also reading each other's work. For example, Mike Davis, one of the foremost urban theorists when writing his classic text on the development of Los Angeles, City of Quartz (1990), drew inspiration and explanation from Gibson: "William Gibson ... has provided stunning examples of how realist, 'extrapolative' science fiction can operate as prefigurative social theory, as well as an anticipatory opposition politics to the 
cyber-fascism lurking over the horizon" (Davis, 1992, p. 3). Interestingly, Gibson drew inspiration for his dystopian visions of urban and political economy in a future San Francisco from Davis's analysis of the urban politics of Los Angeles and from journals such as The Architectural Review (Featherstone \& Burrows, 1995). In the case of these two authors a recursive relationship between fact and fiction, theorist and novelist, developed. For both types of writer, creativity is contingent and recursive-fiction is produced in relation to fact and vice versa. Neither would have emerged as it did without the other.

\section{Conclusion}

In this chapter I have sought to challenge notions of creativity that suggest it is something innately held and wielded by individuals. I have forwarded a conception of creativity that is contingent-, relation-, and context-driven. As argued in these pages, creativity is a product of skill and talent that is embedded within complex networks of people, things, and places. These networks so profoundly shape creativity through training, inspiration, and critical feedback that creativity cannot be divorced from them. Nobody is a fully formed thinker, and nobody works in isolation. Instead, creative acts are a product of the milieu in which they were conceived and created. Along this line of reasoning, I have suggested that fiction is a product of the world (not just of a single author) and that it does work in the world (in diverse and unforeseen ways). To support my argument, I have examined a set of science-fiction writings, highlighting how the authors draw on a diverse range of sources of inspiration, how the texts are shaped by multiple conversations, and how such works then have influence in the world. This process is particularly well illustrated by the recursive relationship that has developed among some science-fiction writers, academics, and others. It is only by examining the full milieu in which a text was created that one can begin to understand its production and its work in the world.

\section{References}

Besher, A. (1994). RIM. London: Orbit.

Bingham, N. (2002). In the belly of the monster: Frankenstein, food, factisches and fiction. In R. Kitchin \& J. Kneale (Eds.), Lost in space: Geographies of science fiction (pp. 180-192). London: Continuum.

Burrows, R. (1997). Virtual culture, urban social polarisation and social science fiction. In B. Loader (Ed.), The governance of cyberspace (pp. 38-45), London: Routledge.

Chesher, M. (1994). Colonizing virtual reality: Construction of the discourse of virtual reality, 1984-1992. Cultronix 1(1). Retrieved 1999 from http:// eserver.org/cultronix/chesher/

Davis, M. (1990). City of quartz. London: Verso. 
Davis, M. (1992). Beyond blade runner: Urban control, the ecology of fear. Westfield, NJ: Open Magazine Pamphlet Series, No. 23.

Dick, P. K. (1996). Do androids dream of sheep? New York: Ballantine Books (Original work published 1968).

Dodge, M. \& Kitchin, R. (2000). Mapping cyberspace. London: Routledge.

Eyries, J-B. (Ed.) (1812). Fantasmagoriana, ou Recueil d'histoires d'apparitions de spectres, revenants, fantômes, etc. Published in English as Tales of the Dead (1813). London: White, Cochrane.

Featherstone, M. \& Burrows, R. (1995). Cyberspace/Cyberbodies/Cyberpunk: Cultures of technological embodiment. London: Sage.

Gibson, W. (1984). Neuromancer. London: HarperCollins.

Gibson, W. (1986). Count zero. London: HarperCollins.

Gibson, W. (1988). Mona Lisa overdrive. London: HarperCollins.

Gibson, W. (1989). High tech high life: William Gibson and Timothy Leary in conversation. Mondo 2000, No. 7 (Fall), 58-64.

Gibson, W. (1992). Virtual light. London: Penguin.

Gibson, W. (1993). Cyberpunk rides again? From Los Angeles to Hong Kong in search of urban futures, interviewed by Bob Catterall. Regenerating Cities, 6, 29-33.

Hayward, P. (1993). Situating cyberspace: The popularisation of virtual reality. In P. Hayward \& T. Wollen (Eds.), Future visions: New technologies of the screen (pp. 180-204). London: British Film Institute.

Hollinger, V. (1991). Cybernetic deconstructions: Cyberpunk and postmodernism. In L. McCaffery (Ed.), Storming the reality studio: A casebook of cyberpunk and postmodern fiction (pp. 203218). London: Duke University Press.

Jameson, F. (1991). Postmodernism, or, the logic of late capitalism. Durham, NC: Duke University Press.

Kitchin, R. \& Kneale, J. (2001). Science fiction or future fact? Exploring the imaginative geographies of the new millennium. Progress in Human Geography, 25, 17-33.

Klein, M. N. (1991). Building blade runner. Social Text, 28, 147-152.

Kneale, J. \& Kitchin, R. (2002). Lost in space. In R. Kitchin \& J. Kneale (Eds.), Lost in space: Geographies of science fiction (pp. 1-16). London: Continuum.

Malmgren, C. D. (1991). Worlds apart: Narratology in science fiction. Bloomington, IN: Indiana University Press.

McCaffery, L. (1991). Introduction: In the desert of the real. In L. McCaffery (Ed.), Storming the reality studio: A casebook of cyberpunk and postmodern fiction (pp. 1-16). London: Duke University Press.

Stephenson, N. (1995) The diamond age. New York: Bantham Books.

Sterling, B. (1988). Islands in the net. New York: Ace Books.

Sterling, B. (1996). Holy fire. New York: Bantham Books.

Stone, A. R. (1991). Will the real body please stand up? Boundary stories about virtual cultures. In M. Benedikt (Ed.), Cyberspace: First steps (pp. 81-118) Cambridge, MA: MIT Press.

Suvin, D. (1979). Metamophoses of science fiction: On the poetics and history of a literary genre. New Haven, CT: Yale University Press.

Tomas, D. (1991). Old rituals for new space: Rites de passage and William Gibson's cultural model of cyberspace. In M. Benedikt (Ed.), Cyberspace: First steps (pp. 31-48). Cambridge, MA: MIT Press.

Walker, J. (1988). Through the looking glass: Beyond user interfaces. White Paper. Retrieved November 21, 2007, from http://www.fourmilab.ch/autofile/www/ chapter2 69.html

Williams, T. (1996). Otherland. London: Orbit. 